\title{
Enzymatic Ultracentrifugation
}

National Cancer Institute

\section{Source}

National Cancer Institute. Enzymatic Ultracentrifugation. NCI Thesaurus. Code C122164.

An ultracentrifug ation based method that uses enzymatic catalytic reaction to quantify a substance, which has been separated in solution by an ultracentrifugation process. 